\title{
Cigarette smoking and attention: processing speed or specific effects?
}

\author{
Giovanna Mancuso ${ }^{1} \cdot$ Marc Lejeune $^{2} \cdot$ Marc Ansseau $^{1}$ \\ ${ }^{1}$ Service de Psychiatrie et Psychologie Médicale, CHU de Liège, Avenue de l'Hôpital, 13 (B35), Sart Tilman, \\ 4000 Liège, Belgium \\ 2Unité de Recherche en Psychologie Clinique et Sociale, Université de Louvain, Place du Cardinal Mercier, \\ 10, 1348 Louvain-la-Neuve, Belgium
}

KEYWORDS: nicotine, human cognition, motricity, reaction time, cigarette

\section{ABSTRACT}

Rationale: It has been evidenced that nicotine acts on some dimensions of human attention. Objective: This study was carried out to test whether the positive effects of nicotine usually observed on the posterior system are specific or should rather be explained in terms of an effect of nicotine on eye movement velocity. Methods: Ten participants were submitted to four tasks assessing attention. The tasks were borrowed from Zimmermann and Fimm's Battery for the Assessment of Attention: alert, eye movements, visual search and incompatibility. The order of the different tasks was balanced among participants. A within-subjects repeated-measure design was used. Participants received a $0.9-\mathrm{mg}$ or $0.1-\mathrm{mg}$ nicotine cigarette. The $0.1-\mathrm{mg}$ cigarette was used as control. The order of administration of doses over sessions was counterbalanced. During the testing day, volunteers smoked their own cigarette and then waited $3 \mathrm{~h}$ without smoking. At the end of this abstinence period, participants completed the baseline tests before smoking an experimental cigarette ad libitum. They were then tested again. Results. Participants who received nicotine appeared to respond faster in an eye movement task - a task associated with a non-elaborated attentional process. Similarly, their alert state improved. On the contrary, no effect of nicotine was observed in the incompatibility task and in the visual search task depending on elaborated attentional process. Conclusions: Data support previous observations and suggest that, first, non-elaborated information processing appeared to be more sensitive to nicotine and, second, this effect is not due to a velocity factor. 


\section{Introduction}

It has been evidenced that nicotine acts on several information processing systems related to attention (for extensive review see Sherwood 1993; Heishman et al. 1994). These effects seem to be due to drug per se and are not the consequence of a reversal effect of a withdrawal induced deficit (Mancuso and Ansseau, unpublished results; Wesnes and Warburton 1984; Le Houezec et al. 1994; Warburton and Arnall 1994; Foulds et al. 1996).

Although several papers have reported nicotine effects on attention, one should make clear which aspects of attention are involved. The multiplicity of concepts and theories used in cognitive psychology does not make the study of attention easy.

To facilitate the understanding of this issue, Van Zomeren and Brouwer (1994) qualified attention in terms of selectivity and intensity. Intensity is involved in tasks requiring energetic resources, attentional resources or effort (i.e. sustained attention). In contrast, selectivity is necessary in focused attention tasks (which involve excluding competing information) or divided attention tasks (requiring attention to be shared between two or more sources of information). Their classification appeared to be useful in psychopharmacological studies: nicotine appears to act on the intensity dimension of attention, whilst a tiny or no effect is observed on the selectivity dimension (Heishman et al. 1994; Mancuso et al. 1999).

However, other approaches continued to be developed to analyse the attentional system. Among others, using a neural network approach, Posner and Petersen (1990) suggested that attention can be mainly separated into three systems. A first system, called the posterior attention system, is localised in the parietal lobes and involves the sensory representations. The major component of the posterior system is usually referred to as covert orienting which processes the spatial accuracy in a selected visual area. A second system, the anterior attention system, is rather localised in the cingulate and the right frontal lobe. It is responsible for action planning and control functions. Finally, a third dimension, located in the right pre-frontal lobe, seems to be involved in alertness and vigilance. Alertness involves a change in the internal state (Homan et al. 1987). Although the posterior system and alertness seem to be sustained by two independent neural networks (Witte and Morrocco 1997), interactions seem to exist between the two networks. For example, in a covert-orienting experiment, a cue orients the organism to the target location and increases the alertness level (Humphreys et al. 1992).

It could be suggested that nicotine should predominantly act on the posterior system and alertness. Indeed, Ghatan et al. (1998) have demonstrated that, with nicotine, the regional cerebral blood flow (rCBF) decreases in the anterior cingulate cortex and in the cerebellum, whilst it increases in the occipital cortex. Moreover, in both humans and rhesus monkeys, the nicotinic cholinergic system is involved in visual spatial attention which is part of the posteripr system. Positive effects of nicotine have been observed on covert orienting (Witte and Morrocco 1997; Murphy and Klein 1998). These effects have been confirmed by investigations using amino-3-hydroxy-5-methyl-4-isox-azole propionic acid (AMPA). This drug, which produces selectively a lesion in the basal forebrain cholinergic system (BFCS) both in monkeys and rats, impaired attention function, but not learning and memory (Muir et al. 1994; Voytko et al. 1994). 
Specifically, covert orienting in visuo-spatial attention was impaired in monkeys (Voytko et al. 1994).

Despite this evidence, no study has specifically tested whether nicotine acts on eye movement velocity, although it might complete the understanding of the present issue. On one hand, it would assess the impact of nicotine on a motor movement as it has already been demonstrated in animals (Ksir et al. 1987). On the other hand, saccades and attention are related: the posterior cortex contributes to saccades programming, and covert attention has been considered to be one step in this process (Posner 1980). Eye movements are determinant in everyday life since highresolution vision is only available in the foveal area. The low resolution of the parafoveal and peripheral vision is rarely consciously experienced since saccadic eye movements allow us to keep a good resolution of the on-line processed visual information related to spatial attentional tasks (Posner 1980; Sheliga et al. 1994).

Indeed, spatial attention helps to select subsequent targets (Eriksen and Hoffman 1973; Hoffman 1975; Posner et al. 1978; Posner 1980; Hoffman and Nelson 1981). Since shifts of attention can occur much faster than changes in eye position (Hoffman 1975), spatial attention can be used during one fixation to select the following one. Posner (1988) has suggested that shifting attention to the target involves an interruption of an ongoing activity (disengage from a focused point), a displacement of attention to a new location (shift to another focus), and the reengagement of attention. Hoffman and Subramaniam (1995) showed that a saccade towards a peripheral point in the visual field involves first orienting attention to that location prior to the saccade execution. Consequently, orienting the attention may be an essential component of preparing and/or executing saccades.

As a consequence, to study simultaneously spatial attention and eye movement appears to be crucial in the understanding of nicotinic effects. Indeed, both oculomotor functions and spatial attention depend crucially on the posterior parietal cortex (Corbeta et al. 1993, 1996; Nobre et al. 1997). In addition, it is well established that nicotine interacts with the dopaminergic pathway inducing an enhancement of the psychomotor activity (Ksir et al. 1987). This enhancement could explain the beneficial effects of nicotine on some attentional tasks.

This study was carried out to test whether the positive effects of nicotine usually observed on the posterior system are specific or should rather be explained in terms of an effect of nicotine on eye movement velocity. Four tasks, related to different aspects of attention, have been used. Among them, two tasks tapped top-down components: focussed attention and visual search. Both components depend on executive functions which are related to frontal lobes activation. Focussed attention is measured through a task which assesses the sensitivity to interference (incompatibility between stimulus and response). Participants have to be active: they have to inhibit irrelevant stimuli. Visual search task was also used since it is highly related to eye movements and requires internally generated decisions for which pre-frontal cortex is crucial. A third task measured the effects of nicotine on eye movements velocity. This task was selected since saccades and covert attention are highly related (see above). Finally, a fourth task assessed the general arousal effect of nicotine (alertness). According to the reviewed literature on attention and nicotine, it was predicted that nicotine should act on eye movement and on alertness. 


\section{Methods and apparatus}

\section{PARTICIPANTS}

Ten volunteers (mean \pm SD age $22.11 \pm 1.9$ years old) from the University of Liège acted as participants. They had all been smokers for more than 2 years ( $4.4 \pm 1.9$ years) and smoked, on average, 17.2 \pm 7 cigarettes per day. Eight subjects smoked cigarettes containing at least $0.9 \mathrm{mg}$ nicotine and two smoked cigarettes containing $0.7 \mathrm{mg}$ nicotine. Participants were given course credits for their participation. Written informed consent was given by the participants in the presence of a person who was not involved in the study. The university ethics committee approved the protocol of the study. All participants abstained from caffeinated products and alcohol overnight. All participants had normal or corrected to normal vision.

\section{COGNITIVE TESTS}

The tasks used in this experiment are part of Zimmermann and Fimm's Battery for the Assessment of Attention (French version: Tests d'évaluation de l'attention (T.E.A.), version 1.02, adapted by North, Leclercq, Crémel, Tassi and Jeromin 1994). The T.E.A. manual does not provide detail about timing or description of stimuli. For this reason, this information is not reported in this paper. For any replication, the use of Zimmermann and Fimm's battery is required. The computer screen used for testing should measure $32 \mathrm{~cm}$ (diagonal), and subjects should be seated $60 \mathrm{~cm}$ from the screen to preserve a similar visual angle size. Four tasks were used: alertness, eye movements, visual search and incompatibility.

\section{ALERTNESS}

This task measures subject's "alertness" or "arousal" level. It deals with the participant's ability to increase his/her attentional level when a stimulus is expected. A visual stimulus (a cross) is presented in the centre of the screen. An auditory signal precedes the target or not. When an auditory signal precedes the visual target, the time between the signal and the target varies from trial to trial. The participant has to react as quickly as possible when the target is displayed. Reaction times (RTs) are recorded. The task is based on an ABBA schema ( $A=$ without auditory signal; $B=$ with auditory signal). Twenty stimuli are presented in each series.

\section{EYE MOVEMENT}

This task does not record the eye movements per se, but rather measures indirectly the latencies for saccadic eye movements. Participants are instructed to stare at a square presented in the centre of the screen. They are required to detect as quickly as possible a target, which can appear on the right or on the left of the central square or be superimposed on the central square. The target is a square notched on its topside whilst the distracter is not (Fig. 1). The target shape is drawn in such a way that participants have to stare at it for detection. In a first condition, the fixation point disappears just before the display of the target (called GAP condition). In a second condition, the fixation point remains visible while the target is presented (OVERLAP condition). 
As a consequence, in this second condition, in addition to a saccade, participants have to disengage attention from the fixation point. Participants have to depress on a key as quickly as possible only when the target appears. RTs are recorded. Time for saccades is derived from (time associated with a response to a stimulus presented on the right or left) minus (time associated with a response to a stimulus centrally presented). This result is supposed to approximate the time for the eye movement only. One hundred stimuli are presented.

\section{VISUAL SEARCH}

This test measures visual scanning ability. A $5 \times 5$ matrix of squares is displayed on the computer screen. Each square is nicked on one side as represented in Fig. 2. Participants have to detect as quickly as possible whether the target is present within the matrix. The target is a square which is nicked on its upper side. A hundred stimuli have been presented with $50 \%$ of trials containing the target (ten by row and column).

\section{INCOMPATIBILITY}

This task attempts to assess the sensitivity to interference due to an incompatibility between the stimulus and the response. Arrows are presented on the right or on the left of a fixation point. The arrow points to the right or to the left. Participants have to react to the arrow direction. The right hand is used when the arrow is pointing to the right, whilst the left hand is used when the arrow is pointing to the left, whatever the arrow position on the screen (left versus right). There is compatibility when the arrow is displayed on the side corresponding to the answering hand. On the contrary, there is incompatibility when the hand and the arrow are on opposite sides. Sixty stimuli are presented (15 stimuli compatible and incompatible in each visual hemifield).

\section{PROCEDURE}

All participants were submitted to the four tasks. The tasks were generated on a computer (screen diagonal size $=32 \mathrm{~cm}$ ), and all responses were recorded. A response keypad was placed directly in front of the subject. Participants were tested individually in a dark room, seated at about $60 \mathrm{~cm}$ from the computer screen. A chin rest was used to avoid head and body movements. The testing began when the subjects eyes had adapted to darkness. The order of the different tasks was balanced between participants.

Each participant attended a preliminary session in which the experimental details were explained. A within-subjects repeated-measure design was used. There were two experimental sessions in which participants received an experimental standard brand of cigarette: in the first, the participants received a cigarette with an ineffective nicotine dose $(0.1 \mathrm{mg})$ and, in the other, they received a cigarette with an effective nicotine dose $(0.9 \mathrm{mg})$. The $0.1-\mathrm{mg}$ cigarette was used as control (Rusted 1996). The sessions were separated by at least 1 week. The order of administration of doses over sessions was counterbalanced. During the testing day, volunteers smoked their own cigarette and then waited $3 \mathrm{~h}$ without smoking. At the end of this abstinence period, participants completed the baseline tests before smoking an experimental cigarette ad libitum (Morgan and Pickens 1982). They were then tested again. The whole session took about 
25 min per volunteer. Before and after the subject smoked a cigarette, the tidal breath carbon monoxide (CO) was measured to check, on one hand, that s/he did not smoke during the abstinence period and, on the other, that $\mathrm{s} /$ he inhaled the cigarette smoke.

\section{ANALYSES}

All data were analysed using analyses of covariance (ANCOVA), always using the baseline as covariate. Tukey's HSD test, derived from the mean square of the relevant interaction terms, was used to assess the main effects of nicotine and the meaningful differences between means on the interactions. Statistical significance was set at $\mathrm{P}<0.05$. To attest the equivalence of baselines across the two sessions (drug and placebo), ANOVAs were computed for each task.

In the incompatibility task, RTs for correct responses and correct detections were analysed using a one-way ANCOVA which incorporated drug treatment (nicotine or placebo) as a withinparticipants factor. In the alert task, RTs were analysed using a two-way ANCOVA that incorporated drug treatment (nicotine or placebo) and auditory signal (present or absent) as within-participants factors. In the visual search task, the same analyses were computed on RT for correct responses and correct detection with drug treatment (nicotine or placebo) and target (present or absent) as within-participants factors. Hits were measured when the target was present, and correct rejections were measured when the target was absent. Finally, in the eye movement task, RTs for correct responses and correct detection were analysed using a threeway ANCOVA with drug treatment (nicotine or placebo), condition (GAP or OVERLAP) and stimulus location (central or left/right) as within-participants factors. Concerning the stimulus location, the left and right locations were collapsed, since we estimated that time for a leftoriented eye movement should be identical to a right-oriented movement. This allowed us to infer the time for the eye movement (see Methods).

Figure 1. Eye movement task

Fixation stimulus

OVERLAP condition / left
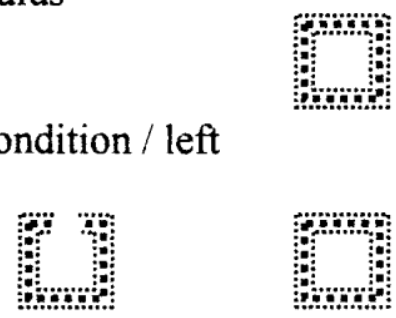

GAP condition / right

Central target
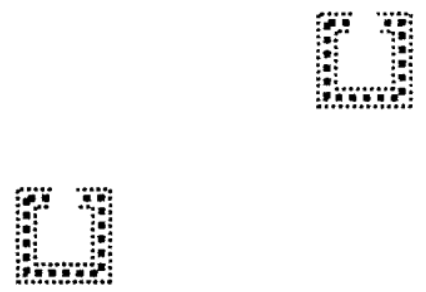


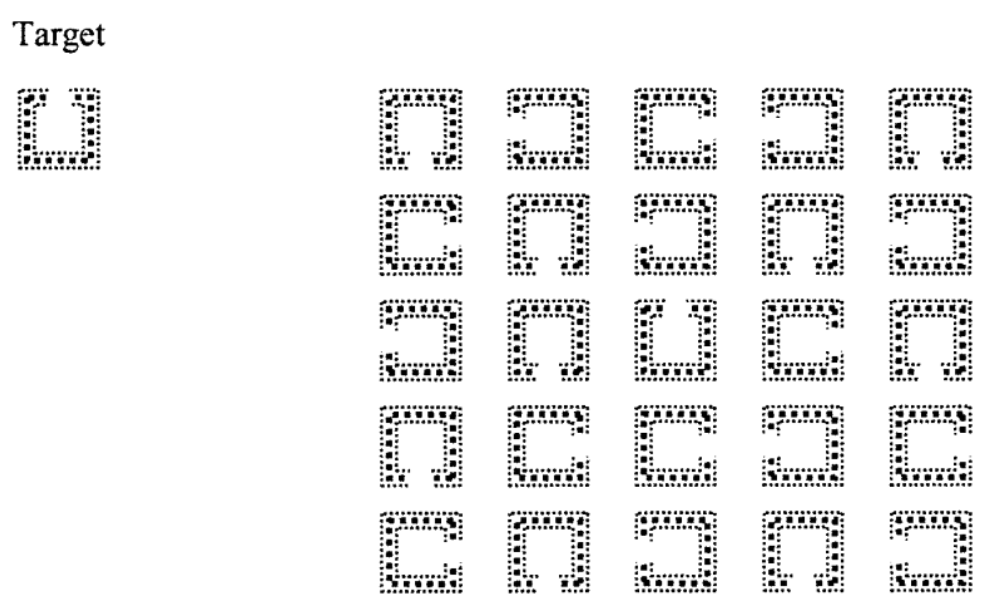

\section{Results}

\section{BASELINES}

No difference was observed among the baselines across sessions (nicotine and placebo) for all tasks $(F<1)$.

\section{INCOMPATIBILITY TASK}

The analyses showed no significant effect of nicotine on RTs or on correct detection $(F<1)$. The data are shown in Table 1 and Fig. $3 a$.

\section{ALERTNESS TASK}

The analysis showed significant main effects of drug treatment $\left(F_{1,8}=6.36, P<0.035\right)$ and presence/absence of the auditory signal $\left(F_{1,8}=6.20, P<0.037\right)$, with faster RTs with nicotine and when the auditory signal preceded the target. The interaction between the two independent variables was not significant $(F<1)$. Data are reported in Table 1 and Fig. 3b.

\section{VISUAL SEARCH TASK}

The analysis showed no significant effect of drug treatment and target presence/absence on RT $(\mathrm{F}<1)$ and no significant interaction between the variables $\left(F_{1,7}=1.68, P>0.23\right)$. Similarly, no significant effect was observed for drug treatment on correct detection $\left(F_{1,7}=3.57, P=0.10\right)$, both for hits and correct rejections since the $\mathrm{F}$ value for target presence/absence and the interaction between variables did not reach 1 (Table 1 and Fig. 3c). 


\section{EYE MOVEMENTS TASK}

Correct detection was always superior to $10 \%$ which prevailed from further analyses. Analyses were carried out on two sets of RTs: (a) global RTs, referred to as RTa, are derived from eye movement plus hand motor response and (b) time for saccades (RTb) as described in the Methods.

Considering RTa, the analysis showed significant main effects of drug treatment $\left(F_{1,7}=6.41\right.$, $\mathrm{P}<0.039$ ), with faster RTs with nicotine. Similarly, a significant effect of condition (GAP versus OVERLAP; $F_{1,7}=5.99, P<0.044$ ) and of stimulus location (centre versus right/left; $F_{1,7}=8.30$, $P<0.023)$ was reported. In addition, the interaction between drug treatment and stimulus location was significant $\left(F_{1,7}=5.85, P<0.046\right)$. A Tukey HSD post-hoc test showed that nicotine affected RTa when the target was presented on the left or right $(P<0.009)$ but not when it was centrally presented $(P=0.16)$. Neither the double interaction between drug treatment and condition nor the triple interaction between the independent variables was significant $(F<1)$.

When RTb is considered, a significant difference between nicotine and placebo is still observed $\left(F_{1,7}=5.85, P<0.046\right)$, but rather interpreted as an effect of alertness. In Fig. 4 , it can be observed that nicotine helps to preserve the baseline performance. The main effect of condition (GAP versus OVERLAP; $F_{1,7}=1.93, P>0.21$ ) and the interaction between drug treatment and condition $\left(F_{1,7}=1.68, P>0.24\right)$ were not significant. Despite these two non-significant effects and considering Fig. 4, further post-hoc analyses have been carried out. Indeed, the significant effect of nicotine might be due to averaging the two conditions. When the two conditions (GAP and OVERLAP) were analysed separately with Tukey HDS test, nicotine decreased RTb in the OVERLAP condition ( $P=0.07)$ but not in the GAP condition $(P=0.57)$. On the basis of this effect, which almost reached significance, it could be suggested that nicotine could mainly act on the disengagement of attention.

Table 1. Means and standard deviations for the different tasks and conditions

\begin{tabular}{|c|c|c|c|c|c|c|c|}
\hline & & \multicolumn{3}{|c|}{$0.1 \mathrm{mg}$ Nicotine } & \multicolumn{3}{|c|}{$0.9 \mathrm{mg}$ Nicotine } \\
\hline & & Baseline & Test & Difference & Baseline & Test & Difference \\
\hline \multicolumn{8}{|c|}{ Alertness test } \\
\hline & Without signal & $208.9 \pm 36.6$ & $212.3 \pm 47.3$ & +3.411 & $209.5 \pm 31.2$ & $198.7 \pm 29.4$ & -10.8 \\
\hline & With signal & $199.1 \pm 26.7$ & $195.5 \pm 28.5$ & -3.68 & $204.1+37.5$ & $191 \pm 26.2$ & -13.1 \\
\hline \multicolumn{8}{|c|}{ Incompatibility test } \\
\hline & Reaction time & $396 \pm 87.2$ & $372 \pm 41.3$ & -23.7 & $397 \pm 74$ & $389 \pm 89.3$ & -8.2 \\
\hline & Correct detection & $52.6 \pm 3.7$ & $53.5 \pm 2.9$ & +0.9 & $51.3 \pm 5.5$ & $52.7 \pm 5.1$ & +1.4 \\
\hline \multicolumn{8}{|c|}{ Visual search test } \\
\hline \multicolumn{8}{|c|}{ Reaction times } \\
\hline & Without target & $3429 \pm 590$ & $2895 \pm 714$ & -534 & $3150 \pm 624$ & $2673 \pm 425$ & -478 \\
\hline & With target & $1917 \pm 558$ & $1526 \pm 375$ & -391 & $1761 \pm 348$ & $1506 \pm 296$ & -256 \\
\hline \multicolumn{8}{|c|}{ Correct detection } \\
\hline & Without target & $48.8 \pm 0.8$ & $49.33 \pm 0.7$ & +0.5 & $49 \pm 0.6$ & $48.8 \pm 0.7$ & -0.2 \\
\hline & With target & $46.1 \pm 2.5$ & $48.3 \pm 1.1$ & +2.2 & $47.8 \pm 1.9$ & $47.7 \pm 2.6$ & -0.1 \\
\hline \multicolumn{8}{|c|}{ Eyes movement test } \\
\hline \multicolumn{8}{|c|}{ Reaction times } \\
\hline Gap & Side & $414.8 \pm 72.1$ & $432.8 \pm 89$ & 17.9 & $419.5+75.4$ & $412.1 \pm 73.5$ & -7.4 \\
\hline & Middle & $391.3 \pm 82$ & $386.8 \pm 71.8$ & -4.4 & $390.4 \pm 69.5$ & $374 \pm 63.7$ & -16.3 \\
\hline \multirow[t]{2}{*}{ Overlap } & Side & $458.3 \pm 71.7$ & $476 \pm 91.1$ & 17.6 & $459.6 \pm 75.2$ & $444.2 \pm 68.1$ & -15.4 \\
\hline & Middle & $453.3 \pm 60.5$ & $450.7 \pm 78.6$ & -2.5 & $442 \pm 62.9$ & $437.1 \pm 68$ & -4.8 \\
\hline
\end{tabular}


Figure 3. Effects of $0.9 \mathrm{mg}$ nicotine (white bars) and $0.1 \mathrm{mg}$ nicotine (black bars) on the mean reaction time for correct responses measured for the incompatibility (a), alert (b), visual search (c) and eye movement task (d). Only change scores are reported (test minus baseline). Vertical brackets represent the pooled SEM (X2) related to the change. *Reached significant difference at $<0.05$
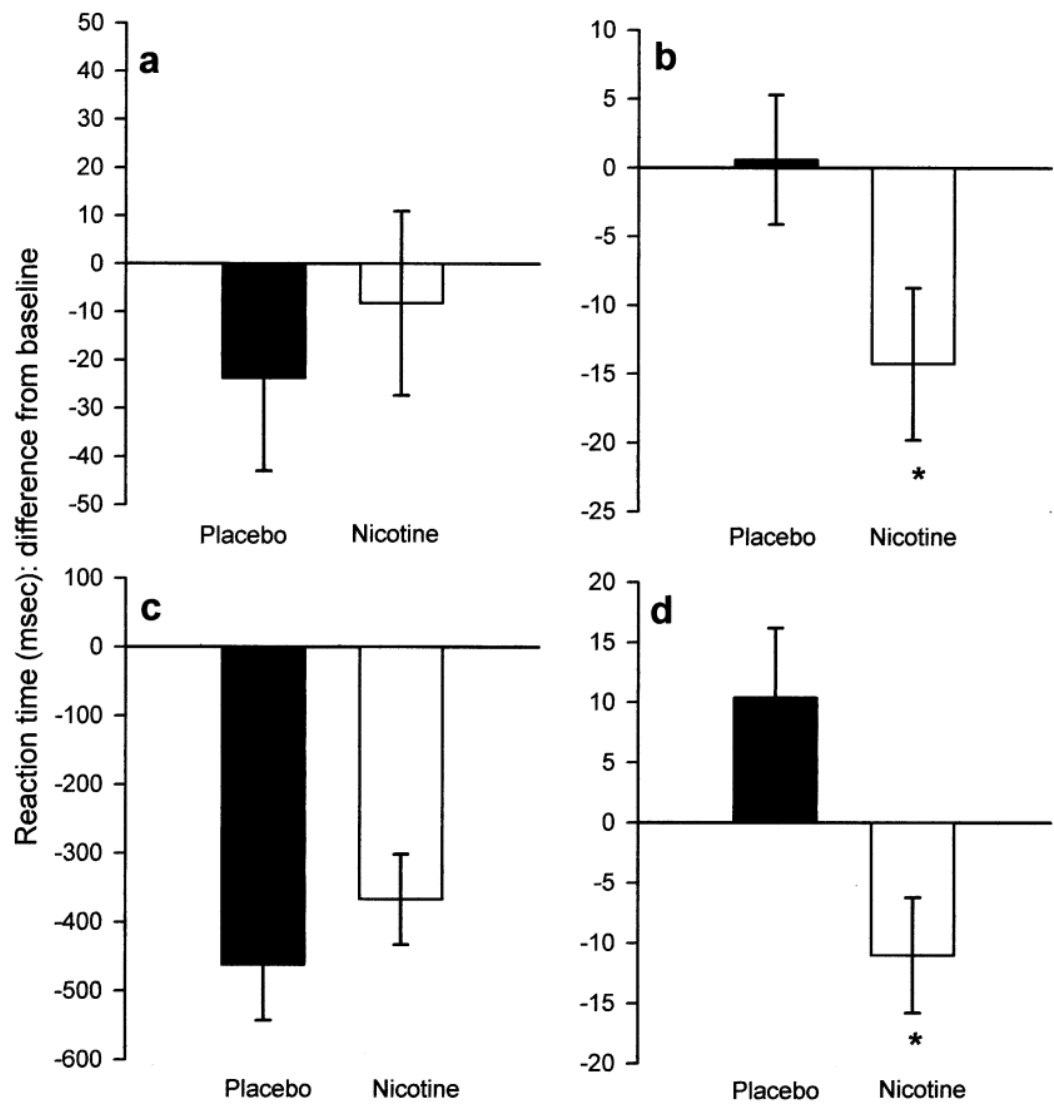

\section{Discussion}

In this study, participants who received nicotine appeared to respond faster in the eye movement task - a task associated with a non-elaborated attentional process (intensity feature of attention). Similarly, their alert state improved. On the contrary, no effect of nicotine was observed in the incompatibility task and in the visual search task depending on elaborated attentional process (selectivity feature of attention). Thus, these data support the observations of Mancuso et al. (1999), which suggested that nicotine acts specifically on the intensity dimension of attention. In other words, effortless information processing appeared to be more sensitive to nicotine.

Currently, cognitive scientists intend to decompose the sub-systems involved in psychological functions, such as memory and attention (Kosslyn and Andersen 1992). This approach, used by Posner and Petersen (1990) to study attention, should help in identifying which attentional components are sensitive to nicotine and in which brain areas nicotine is involved.

On the basis of our chronometric data, it could be suggested that nicotine affects the posterior attentional system involved in covert orienting, eye movement and vigilance (alert state) but not the anterior attentional system involved in focussed attention (incompatibility) and visual 
search. It supports studies that demonstrate that both in smokers and non-smokers - with the same nature and magnitude - nicotine decreases rCBF in the anterior cingulate cortex and the cerebellum and, simutaneously, increases rCBF in the posterior system (Ghatan et al. 1998). Furthermore, it is consistent with the potential effect of nicotine on the posterior system. Nicotine facilitates covert orienting in humans (Witte et al. 1997; Murphy and Klein 1998), in animals with BFCS lesions (Voytko et al. 1994) and in humans suffering from DAT (Parasuraman et al. 1992; Oken et al. 1994; Maruff et al. 1995). This set of evidences suggests a specific role of the nicotinic cholinergic system in visual orienting and supports the general assumption that specific attentional processing is mediated by distinct neural subsystems.

Another interpretation could be offered to explain the nicotine properties. The effect of nicotine in tasks involving tiny or no elaborated information processing could be explained by an aspecific major factor such as the processing speed (Salthouse 1991). In complex tasks, RTs are usually longer than in simple tasks. As a consequence, the discrete positive effect of nicotine shown in such tasks could be masked in a higher inter-individual variability. We are tempted to reject this interpretation on the basis of RTs collected in the eye movements task. Indeed, in this simple task, RT values were very similar to those observed in the incompatibility task (Table 1).

The significant effect on global RTs in the eye movement task could also be interpreted as the result of an elevation of the arousal state, just as in the alert task. However, further analyses have shown that the improvement in the eye movement task is not only due to an effect of nicotine on occulomotor velocity. When the two conditions (GAP and OVERLAP) were analysed separately, only the RTs in the OVERLAP condition were affected by nicotine. It suggests that nicotine does not affect saccades velocity but rather acts on the disengagement of attention from a focussed point. These observations are congruent with Shepherd et al. (1986) who reported evidence for a closer relationship between attention and peripheral cue than between attention and saccades. In addition, the absence of significant differences between nicotine and placebo in the visual scanning task supports the idea that the improvement observed on the eye movement task is not due to eye movement velocity.

In conclusion, this study supports the hypothesis that nicotine facilitates specifically nonelaborated information processing. Nicotine is mainly involved in the posterior attentional processes, and its effects are not due to an increase of eye movement velocity. 
Figure 4. Effects of $0.9 \mathrm{mg}$ nicotine (white bars) and $0.1 \mathrm{mg}$ nicotine (black bars) on the mean reaction time measured on eye movement latency (a) and on eye movement gap and overlap condition (b). Only change scores are reported (test minus baseline). Vertical brackets represent the pooled SEM (X2) related to the change. ${ }^{*}$ Reached significant difference at $P<0.05 ;{ }^{*}$ Reached significant difference at $P<0.10$

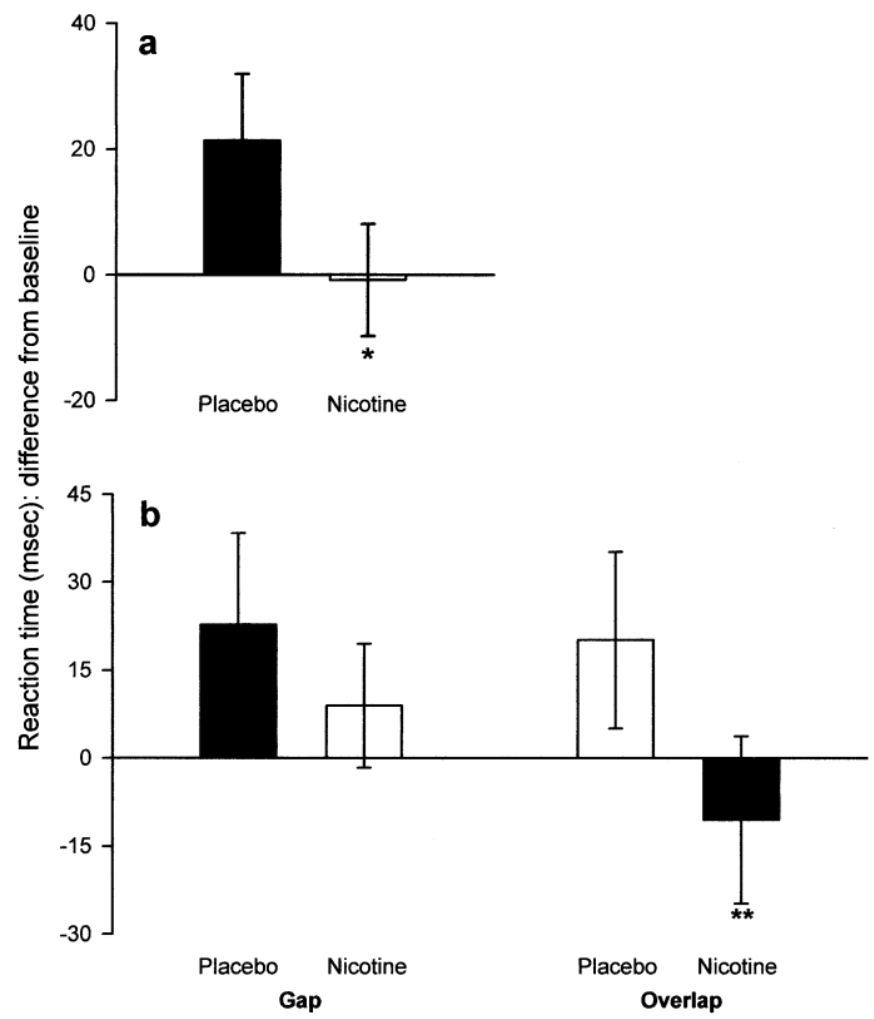

Acknowledgements The authors are grateful to Cédric Laloyaux for his help in data gathering. Giovanna Mancuso was a member of the Laboratory of Psychopharmacology and Biopsychology, and Marc Lejeune was a member of the Laboratory of Cognitive Psychology, both at the University of Liège, when this experiment was carried out. 


\section{References}

Corbeta M, Miezin FM, Shulman GL, Petersen SE (1993) A PET study of visuaspatial attention. J Neurosci 13:1202-1226

Corbeta M, Shulman GL, Miezin FM, Petersen SE (1996) Superior parietal cortex activation during spatial attention shifts and visual feature conjunction. Science 270:802-805

Eriksen CW, Hoffman JE (1973) The extent of processing of noise elements during selective visual encoding from visual displays. Percept Psychophysics 14:155-160

Foulds J, Stapleton J, Swettenham J, Bell N, MeSoricy K, Russell MA ( 1996) Cognitive performance effects of subcutaneous nicotine in smokers and never-smokers. Psychopharmacology 127:31-38

Ghatan PH, Ingvar M, Eriksson L, Stone-Elander S, Serrander M, Ekberg K, Wahren J (1998) Cerebral effects of nicotine during cognition in smokers and non-smokers. Psychopharmacology 136:179-189

Heishman SJ, Taylor RC, Henningfield JE (1994) Nicotine and smoking: a review of effects on human performance. Exp Clin Psychopharmacol 2:345-395

Hoffman JE (1975) Hierarchical stages in the processing of visual search. Percept Psychophysics 18:348354

Hoffman JE, Nelson B (1981) Spacial selectivity in visual search. Percept Psychophysics 30:283-290

Hoffman JE, Subramaniam B (1995) The role of visual attention in saccadic eye movements. Percept Psychophysics 57:787-795

Homan et al. (1987) Alertness involves a change in the internal state.

Humphrey GW, Freeman TA, Muller HJ (1992) Lesioning a connectionist model of visual search: selective effects on distractor grouping. Can J Psychol 46:417-427

Kosslyn SM, Andersen RA (1992) Frontiers in cognitive neuroscience. MIT Press, Cambridge, MA

Ksir C, Hakan RL, Kellar KJ (1987) Chronic nicotine and locolotor activity: influences of exposure dose and test dose. Psychopharmacology 92:25-29

Le Houezec J, Halliday R, Benowitz NL, Callaway E, Naylor H, Herzig K (1994) A low dose of subcutaneous nicotine improves information processing in non-smokers. Psychopharmacology 114:628-634

Mancuso G, Warburton DM, Mélen M, Sherwood N, Tirelli E (1999) Selective effects of nicotine on attention processes. Psychopharmacology 146:199-204

Maruff P, Malone V, Currie J (1995) Asymetries in the covert orienting of visual spatial attention to spatial and non-spatial cues in Alzheimer's disease. Brain 118:1421-1435

Morgan SF, Pickens RW (1982) Reaction time performance as a function of cigarette smoking procedure. Psychopharmacology 77:383-386

Muir JL, Everitt BJ, Robbins TW (1994) AMPA-induced excitotoxic lesions of basal forebrain: a significant role for the cortical cholinergic system in attentional function. J Neurosci 14:2313-2326

Murphy FC, Klein RM (1998) The effects of nicotine on spatial and non-spatial expectancies in a covert orienting task. Neuropsychologia 36:1103-1114 
Nobre AC, Sebestyen GN, Gitelman DR, Mesulam MM, Frackowiak RS, Fritz CD (1997) Functional localization of neural network for visual spatial attention by positron emission tomography. Brain $120: 515-533$

Oken BS, Kishiyama MA, Kaye JA, Howieson DB (1994) Attention deficit in Alzheimer's disease is not simulated by an anticholinergic/antihistaminergic drug and is distinct from deficits in healthy aging. Neurology 44:657-662

Parasuraman R, Greenwood PM, Haxby JV, Grady CL (1992) Visuospatial attention in dementia of the Alzheimer type. Brain 115:711-733

Posner MI (1980) Orienting of attention. Q J Exp Psychol 32:3-25

Posner MI (1988) Stuctures and functions of selective attention. In: Boll T, Bryant B (eds) Master lectures in clinical neuropsychology and brain function: research, measurement, and practice. American Psychological Association, Washington, DC, pp 171-202

Posner MI, Petersen SE (1990) The attention system of the human brain. Ann Rev Neurosci 13:25-42

Posner MI, Nissen NJ, Ogden WC (1978) Attended and unattended processing modes: the role of set for spatial location. In: Picks HL, Saltzman IJ (eds) Modes of perceiving and processing information. Erlbaum, Hillsdale, NJ, pp 137-157

Rusted JM, Graupner L, Greenwood K (1996) Methodological considerations in nicotine research: the use of denicotinised cigarettes as the control condition in smoking studies. Psychopharmacology 125:176-178

Salthouse TA (1996) The processing-speed theory of adult age differences in cognition. Psychol Rev 103:403-428

Sheliga BM, Riggio I, Rizzolatti G (1994) Orienting of attention and eye movements. Exp Brain Res 98:507522

Shepherd M, Findlay JM, Hockey RJ (1986) The relationship between eye movement and spatial attention. Q J Exp Psychol 38:475-491

Sherwood N (1993) Effects of nicotine on human psychomotor performance. Hum Psychopharmacol 8:155-184

van Zomeren AH, Brouwer WH (1994) Clinical neuropsychology of attention. Oxford University Press, Oxford

Voytko ML, Olton DS, Richardson RT, Gorman LK, Tobin JT, Price DL (1994) Basal forebrain lesion in monkeys disrupt attention but not learning and memory. J Neurosci 14: 167-186

Warburton DM, Arnall C (1994) Improvements in performance without nicotine withdrawal. Psychopharmacology 115:539-542

Wesnes K, Warburton DM (1984) The effects of cigarettes of varying yield on rapid information processing performance. Psychopharmacology 82:338-342

Witte EA, Morrocco RT (1997) Effects of altering brain cholinergic activity on covert orienting of attention: comparison of monkeys and human performance. Psychopharmacology 132: 1324-1334

Zimmermann P, Fimm B (1994) Test d'Évaluation de l'Attention (TEA). Version 1.02. P. Zimmermann, Psychologisches Institut der Universität Freiburg, Freiburg 